\title{
KARAKTERISTIK KADER DAN EVALUASI PELAKSANAAN KEGIATAN POSYANDU DIWILAYAH KERJA PUSKESMAS PEMBANTU KURAO KECAMATAN NANGGALO KOTA PADANG TAHUN 2019
}

\author{
${ }^{1}$ Ety Aprianti, ${ }^{1}$ Sri Suciana, ${ }^{2}$ Fery Musharyadi, ${ }^{3}$ Yona Firdali Ranti, ${ }^{4}$ Desi Noviayanti, ${ }^{4}$ Yolanda Natasia \\ ${ }^{1}$ Prodi D.III Kebidanan \\ ${ }^{2}$ Prodi D.III Kebidanan \\ ${ }^{3}$ Alumni Prodi D.III Kebidanan \\ ${ }^{4}$ Mahasiswa Prodi D.III Kebidanan \\ STIKes Mercubaktijaya Padang, Jamal Jamil Pondok Kopi Siteba Padang \\ 25146 Telp.(0751)442295 Fax.(0752)442286 \\ Email: etyaprianti@gmail.com
}

Submitted : 25-06-2020, Reviewer:27-06-2020, Accepted: 30-06-2020

\begin{abstract}
ABSTRAK
Posyandu is a health service organized by, from, for and with the community. Padang DKK 2016 Puskesmas pembantu Kurao has a low Posyandu level. The purpose of this study was to find out the description of the implementation of the Kurao posyandu activity in the Working Area of Nanggalo Health Center in 2019.

The purpose of this study was to find out how the Posyandu Cadre Characteristics and Evaluation of Posyandu Activity Implementation in the Work Area of the Kurao SubDistrict Health Center in Nanggalo. This research is a quantitative and qualitative study using primary and secondary data obtained from Health Officers, cadres and the community who come to posyandu

The results obtained were more than half of respondents (56.6\%) with the age category 2645 years. Most respondents $(80 \%)$ were married or married. More than half of respondents (63.4\%) with <5 years old category. Most respondents $(83.4 \%)$ with a secondary education level category. More than half of respondents $(76.6 \%)$ in the category of not working or housewives

A total of 11 posyandu are under the working area of the Kurao Preparation of information on Posyandu implementation is carried out 1 day before the implementation of Posyandu and preparation of facilities, the infrastructure has been completed. In the implementation of posyandu activities, there was an ineffectiveness in the implementation of the fourth table because not all cadres understood and were able to provide counseling materials related to health issues, because not all cadres received specific training. Cadres only get information through regular monthly meetings at cadre social gathering events. The Posyandu Information System has been arranged in detail. Policies, preparation, implementation and Posyandu Information System in the work area of the Kurao sub-pustu have not been prepared and implemented in full, there are still shortcomings. With this research, it is recommended that health workers in the Puskesmas be able to provide training and refreshment to cadres and be able to complete all the deficiencies that exist in the implementation of the posyandu activities
\end{abstract}

Keywords:Posyandu, Posyandu Implementation 


\begin{abstract}
ABSTRAK
Posyandu merupakan langkah yang cukup strategis dalam rangka pengembangan kualitas sumber daya manusia bangsa indonesia agar dapat membangun dan menolong dirinya sendiri, sehingga perlu ditingkatkan pembinaannya. Untuk meningkatkan pembinaan posyandu sebagai pelayanan $\mathrm{KB}$ dan kesehatan yang dikelola untuk dan oleh masyarakat dengan dukungan pelayanan teknis oleh petugas perlu ditumbuh kembangkan perlu serta aktif masyarakat dalam wadah LKMD. Kader adalah seorang tenaga sukarela yang direkrut dari, oleh dan untuk masyarakat, yang bertugas membantu kelancaran pelayanan kesehatan. Keberadaan kader sering dikaitkan dengan pelayanan rutin di posyandu. (Ismawati, Cahyo. Dkk. 2010)

Tujuan penelitian ini untuk mengetahui bagaimana Bagaimana Karakteristik Kader Posyandu dan Evaluasi Pelaksanaan Kegiatan Posyandu di Wilayah Kerja Puskesmas Pembantu Kurao Kecamatan Nanggalo Kota Padang Tahun 2019. Penelitian yang dilakukan adalah metode Deskriptif yaitu menggambarkan atau mendeskripsikan tentang gambaran karakteristik kader posyandu. Penelitian ini merupakan penelitian kuantitaif dan kualitatif dengan menggunakan data primer dan data sekunder yang diperoleh dari Petugas Kesehatan, kader serta masyarakat yang datang ke posyandu pada posyandu di Wilayah kerja Puskesmas Pembantu Kurao Kecamatan Nanggalo Kota Padang Tahun 2019.

Hasil penelitian didapatkan Lebih dari separoh responden $(56,6 \%)$ dengan kategori Umur 26-45 tahun. Sebagian besar responden $(80 \%)$ dengan kategori kawin atau telah menikah. Lebih dari separoh responden $(63,4 \%)$ dengan kategori lama $<5$ tahun. Sebagian besar responden $(83,4 \%)$ dengan kategori Tingkat pendidikan menengah. Lebih dari separoh responden $(76,6 \%)$ dengan kategori Tidak bekerja atau ibu rumah tangga.

Sebanyak 11 posyandu yang berada di bawah wilayah kerja puskesmas pembantu Kurao , dimana tidak ada terdapat SK Pendirian Posyandu, struktur organisasi serta tugas dari masing-masing posyandu di karenakan posyandu tersebut hanya melanjutkan pelimpahan penanggung jawab sebelumnya. Persiapan informasi pelaksanaan posyandu dilaksanakan 1 hari sebelum pelaksanaan Posyandu dan persiapan sarana, prasananya sudah dilengkapi. Pada pelaksanaan kegiatan posyandu terdapat kurang efektifnya pelaksanaan pada meja ke IV dikarenakan belum semua kader memahami dan mampu memberikan materi penyuluhan terkait permasalahan kesehatan, dikarenakan belum semua kader mendapatkan pelatihan secara khusus. Kader hanya mendapatkan informasi melalui pertemuan rutin bulanana di acara arisan kader saja. Terkait Sistem Informasi Posyandu sudah tersusun secara rinci. Kebijakan, persiapan, pelaksanaan serta Sistem Informasi Posyandu di wilayah kerja pustu kurao belum disiapkan dan dilaksanakan secara lengkap, masih ada kekurangannya. Dengan adanya penelitian ini, disarankan kepada tenaga kesehatan yang ada di Puskesmas untuk dapat memberikan pelatihan dan penyegaran kepada kader dan dapat melengkapi segala kekurangan yang ada pada pelaksanaan kegiatan posyandu tersebut..
\end{abstract}

Kata Kunci : Kader, Pelaksanaan Posyandu 


\section{PENDAHULUAN}

Upaya Kesehatan Bersumber Daya Masyarakat (UKBM) adalah wahana pemberdayaan masyarakat, yang dibentuk atas dasar kebutuhan masyarakat, dikelola oleh, dari, untuk dan bersama masyarakat, dengan bimbingan dari petugas puskesmas, lintas sektor, dan lembaga terkait lainnya (Kementrian Kesehatan RI, 2012)

Posyandu merupakan salah satu bentuk UKBM yang dikelola dan diselenggarakan dari, oleh, untuk dan bersama masyarakat dalam penyelenggaraan pembangunan kesehatan, guna memberdayakan masyarakat dan memberikan kemudahan kepada masyarakat dalam memperoleh pelayanan kesehatan dasar untuk mempercepat penurunan angka kematian ibu dan bayi(Prasetyawati, 2012)

Perkembangan jumlah Posyandu di Kota Padang beberapa tahun terakhir mengalami peningkatan, tahun 2010 berjumlah 855 posyandu pada tahun 2011 bertambah 3 Posyandu sehingga total Posyandu sebanyak 858 dan pada tahun 2012 Posyandu yang ada berjumlah 864, tahun 2013 berjumlah 867 posyandu dan tahun 2014 berjumlah 867 posyandu (DKK Padang, 2014)

Pada tahun 2016, kota padang mempunyai 898 posyandu yang tersebar di 104 kelurahan. Berdasarkan stratanya, Posyandu Pratama berjumlah $0.11 \%$, Posyandu Madya 15,14\%, Posyandu Purnama $64,48 \%$ dan Posyandu Mandiri 20,38\% (DKK Padang, 2016)

Berdasarakan dari survey awal yang dilakukan pada tanggal 25 Maret 2019 di Wilayah Kerja Puskesmas
Pembantu Kurao Kecamatan Nanggalo Kota Padang di dapatkan bahwa Puskesmas pembantu Kurao memiliki 11 posyandu dengan tingkatan strata posyandu yaitu strata madya $47,50 \%$ dan strata purnama $52,50 \%$ (DKK Padang,2018)

partisipasi masyarakat (D/S) yang telah tercapai $70,78 \%$ dan cakupan hasil penimbangan (N/D) yang telah tercapai $91,7 \%$. Hambatan dalam pelaksanaan kegiatan posyandu tersebut yaitu ibu balita yang tidak datang ke posyandu untuk melakukan penimbangan berat badan, disebabkan karena ibu balita menganggap imunisasi yang telah lengkap tidak perlu datang ke Posyandu lagi untuk melakukan penimbangan berat badan. Dampak dari pelaksanaan kegiatan Posyandu tersebut yaitu tidak terpantaunya tumbuh kembang balita, sehingga ada balita yang mengalami masalah pada status gizi, dan tidak dapat di inervensi lebih lanjut.

Peran Tenaga Kesehatan (Bidan)
dalam menanggulangi masalah
tersebut yaitu dengan melakukan
kegiatan Sweeping ke rumah-rumah
warga yang memiliki balita yang
tidak dapat mengikuti posyandu,
bersama dengan petugas dari
Puskesmas Ikur Koto. Hal ini
dilaksanakan untuk selalu menjaga
agar balita tersebut terjaga kondisi
kesehatannya. Selain itu asupan gizi
yang seimbang menjadi prioritas dari
petugas penyuluh, kepada ibu balita
untuk selalu memperhatikan makanan
yang bergizi untuk anak mereka.

Berdasarkan survey awal yang dilakukan pada tanggal 26 Maret 2019 pada salah seorang kader posyandu di wilayah kerja puskesmas pembantu Kurao Tahun 2019, 
didapatkan bahwa posyandu memiliki 5 orang kader, namun yang aktif paling banyak 4 orang, dimana kader ini sangat jarang mendapat pelatihan kader, terakhir para kader mendapat pelatihan pada tahun 2014 yang saat itu diadakan oleh mahasiswa praktik.

Keterangan dari kader tersebut didapatkan bahwa posyandu dilaksanakan pada minggu pertama setiap bulannya. Serta didapatkan bahwa fungsi posyandu belum berjalan secara optimal. Dimana Meja keempat atau meja penyuluhan selama ini belum dimanfaatkan penuh oleh kader posyandu. Banyak diantara mereka yang tidak memberikan penyuluhan pada saat penimbangan rutin seriap bulannya, dalam memberikan penyuluhan ada tenaga kesehatan dan ada juga kader, kader dalam memberikan penyuluhan hanya seadanya saja dan tidak mendalam.

Berdasarkan data-data diatas penulis tertarik melakukan penelitian mengenai Bagaimana "Karakteristik Kader Posyandu dan Evaluasi Pelaksanaan Kegiatan Posyandu di Wilayah Kerja Puskesmas Pembantu Kurao Kecamatan Nanggalo Kota Padang Tahun 2019”.

\section{TINJAUAN TEORITIS}

Posyandu adalah kegiatan kesehatan dasar yang di selenggarakan dari, oleh dan untuk masyarakat yang dibantu oleh petugas kesehatan disuatu wilayah kerja puskesmas, dimana program ini dapat dilaksanakan di balai dusun, balai kelurahan, maupun tempat-tempat lain yang mudah didatangi oleh masyarakat (Sulistyorini, 2010)

Posyandu adalah suatu forum komunukasi alih teknologi dalam pelayanan kesehatan masyarakat dari
Keluarga Berencana dari masyarakat oleh masyarakat dan untuk masyarakat dengan dukungan pelayanan serta pembinaan teknis dari petugas kesehatan dan keluarga berencana yang mempunyai nilai strategis untuk pengembangan daya manusia sejak dini (Wahyuningsih, Heni Puji. Dkk.2009)

Untuk meningkatkan kinerja pelayanan Posyandu, pemerintah mengeluarkan Surat Edaran Menteri Dalam Negeri No. 411.3/536/SJ Tahun 1999 dan Surat Edaran Menteri Dalam Negeri No. 411.3/1116/SJ Tahun 2001 tentang Pedoman Umum Revitalisasi Posyandu. Revitalisasi Posyandu bertujuan agar terselenggaranya kegiatan Posyandu secara rutin dan berkesinambungan, tercapainya pemberdayaan tokoh masyarakat dan kader melalui advokasi, orientasi, pelatihan atau penyegaran, dan tercapainya pemantapan kelembagaan Posyandu (Rosihan, 2012)

Tenaga utama pelaksana posyandu adalah kader posyandu, yang kualitasnya sangat menentukan dalam usaha meningkatkan kualitas pelayanan yang dilaksanakan. Dengan demikian, kemampuan kader harus dikembangkan untuk berpotensi secara maksimal, dengan bekal pengetahuan dan keterampilan yang disesuaikan dengan tugas yang diemban, dalam mengelola posyandu, agar dapat berperan aktif dalam meningkatkan kesehatan masyarakat (Departemen Kesehatan RI, 2015)

\section{METODE PENELITIAN}


Penelitian ini merupakan penelitian Mix Methods yaitu penelitian kuantitatif dan kualitatif. Penelitian ini dengan menggunakan data primer dan data sekunder yaitu memperoleh data dari Petugas Kesehatan, Kader serta masyarakat yang datang ke Posyandu Cendrawasih $1 \mathrm{RW}_{3} \mathrm{RT}_{2}$ di Wilayah Kerja Puskesmas Ikur Koto Kota Padang Tahun 2018.Jenis data pada penelitian ini adalah data primer dan data sekunder. Data primer adalah sumber data yang langsung memberikan data kepada pengumpul data (peneliti) berupa pelaksanaan kegiatan posyandu.Data sekunder adalah sumber yang tidak langsung memberikan data kepada Peneliti, misalnya lewat orang lain atau lewat dokumen(Sugiyono, 2013)

Dalam penelitian ini data sekunder diperoleh berupa Surat Keputusan (SK) kader dan Register Kohort. Sumber data yang peneliti gunakan yaitu berupa Place, Person and Paper. Analisa data menggunakan analisa data kualitatif yang disajikan dalam bentuk naratif.

Penelitian kualitatif, analisa data lebih difokuskan selama proses di lapangan bersamaan dengan pengumpulan data (Sugiyono, 2016)

\section{HASIL DAN PEMBAHASAN}

\section{Gambaran Pengorganisasian Pembinaan Pelaksanaan Kegiatan Posyandu Pada Posyandu $\begin{array}{llll}\text { Cendrawasih } 1 & \mathrm{RW}_{3} \mathrm{RT}_{2} & \mathrm{di}\end{array}$ Wilayah Kerja Puskesmas Ikur Koto Tahun 2018.}

Dari hasil wawancara yang telah dilakukan kepada informan yaitu bidan Pembina wilayah dengan menggunakan panduan wawancara didapatkan bahwa nama posyandunya yaitu posyandu Cendrawasih 1 . Saat peneliti melakukan observasi peneliti menemukan bahwa plang nama posyandu tersebut tidak permanen (bongkar pasang). Sebagaimana kutipan dari bidan Pembina wilayah dan coordinator promkes, yaitu :

“....Surat keputusan (SK) pendirian posyandu Cendrawasih ini juga tidak $a d a$, coba tanyakan ke kk $V^{x x x}$ koordinator promkes,biasanya kak vivi itu yang memegang Surat Keputusan (SK) Pendirian Posyandu itu....". (if $1 \mathrm{~N}$ )

“....kalau untuk Surat Keputusan (SK) Pendirian Posyandu ngak ada kami yang megangnya, karena posyandu di Wilayah Kerja Puskesmas Ikur koto ini merupakan pemekaran dari Puskesmas Air Dingin maka untuk SK pendirian posyandunya ngak ada sama kami orang promkes, yang ada sama kami hanya Surat Keputusan (SK) kader.....". (if $2 \mathrm{~N}$ )

Berdasarkan data diatas, posyandu cendrawasih 1 hanya memiliki nama posyandu dan Surat Keputusan (SK) Kader, namun posyandu tersebut tidak memiliki Surat Keputusan (SK) Pendirian Posyandu, struktur organisasi dan tugas pokok dan fungsi dari masing - masing struktur organisasi yang jelas. Hal ini tidak sesuai dengan teori yang dinyatakan oleh Siti Cholisah tahun 2013 bahwa suatu syarat pendirian sebuah organisasi adalah adanya visi dan misi, keselarasan tujuan, adanya struktur jabatan dan adanya pembagian kerja.

\section{Gambaran persiapan pelaksanaan kegiatan pada posyandu}




\section{Cendrawasih 1 di Wilayah kerja Puskemas Ikur Koto Tahun 2018.}

Berdasarkan informasi yang didapatkan dari informen yaitu kader posyandu didapatkan bahwa persiapan pelaksanaan kegiatan posyandu pada posyandu Cendrawasih 1 sudah dipersiapkan dengan baik.Menurut kader persiapan posyandu ini dilaksanakan sebelum pelaksanaan kegiatan posyandu.

\section{Pemberian informasi kepada warga setempat}

“...partamo awak datang karumahrumah warga yang ado mempunyai bayi jo balita tu siap tu awak kecean lai dari muluik ka muluik ka warga tantang ado posyandu di surau gadang bisuak. Sasudah tu baru di umumkan di masjid sahari sabalum posyandu...."

\section{Persiapan tempat dan sarana posyandu}

“....kalau untuak pasiapan tampek yo yang patuik di sapu - di sapu kan meja awak alun ado lai kan, dikecekan alun ado lai ado ciek meja ketek. jadi awak cuman mambantangan tikar samo panyiapkan timbangan samo alat untuak mangukua tinggi badan....".

\section{Persiapan kader dan tenaga kesehatan}

“....untuak pasiapan posyandunyo kalau kader yo manyiapkan tampek posyandunyo kalau bidan manyiapkan imunisasinyo di puskesmas, sasudah alah siap tampeknyo tu baru kami umuman liak di masjid tantang adonyo posyandu kini....".

\section{Persiapan PMT}

“.....kalau PMT nyo di buek di pagi ari pas pelaksanaan kagiatan yandunyo, Yang dibuek tu biasonyo kayak bubua kacang padi, raga raga, talua puyua, pisang smo jeruk, tu ditambang roti dari puskesmas kadang - kadang.....".

\section{Persiapan vaksin dan vitamin}

“....pasiapan vaksin samo vitaminnyo tu disiapkan samo orang puskesmas kalau kader tu ndk ado mampasiapan itu do, kami hanyo mampasiapkan tempat dan sarana kagiatan posyandu istilahnyo cuman manfasilitasi palaksanaannyo sajo....".

Berdasarkan analisa peneliti bahwa persiapan pelaksanaan kegiatan posyandu sudah disiapkan dan sudah dilaksanakan secara lengkap oleh kader, hal ini disebabkan karena semua pengelola sudah mengetahui tugas dan fungsi masing - masing, dan kader yang terlibat pada kegiatan posyandu sudah berpengalaman menjadi kader selama 6 tahun, kader berkoordinasi atau bekerja sama dengan tenaga kesehatan untuk mempersiapkan pelaksanaan kegiatan posyandu.

Hal ini didukung oleh hasil penelitian Yolanda Cicilia Eka tahun 2015 menyebutkan bahwa seluruh kader yang mempunyai pengalaman $1-5$ tahun dalam melakukan suatu kegiatan posyandu dapat meningkatkan kinerja posyandu tersebut, sedangkan menurut Notoadmodjo (2007) pengalaman merupakan sumber pengetahuan, dan pengalaman itu merupakan suatu cara untuk memperoleh kebenaran perilaku, sehingga dapat disimpulakan bahwa semakin banyak pengalaman yang dimiliki seseorang 
maka informasi suatu kegiatan berkembang semakin baik

\section{Gambaran Pelaksanaan Kegiatan Posyandu Pada Posyandu $\begin{array}{llll}\text { Cendrawasih } & 1 & \mathrm{RW}_{3} \mathrm{RT}_{2} & \mathrm{Di}\end{array}$ Wilayah Kerja Puskesmas Ikur Koto Tahun 2018.}

Dari hasil wawancara yang telah peneliti lakukan kepada masyarakat yang menjadi informen, yang melakukan kunjungan ke posyandu dengan menggunakan panduan wawancara tentang pelaksanaan kegiatan posyandu di tinjau dari sistem 5 meja pada Posyandu Cendrawasih $1 \mathrm{RW}_{3} \mathrm{RT}_{2}$ Di Wilayah Kerja Puskesmas Ikur Koto Tahun 2018 yang terdiri dari pendaftaran, penimbangan, pencatatan, penyuluhan dan pemberian pelayanan kesehatan oleh tenaga kesehatan.

“....pada awalnya datang mandaftar di tempat kader, setelah mandaftar lalu melakukan penimbangan Berat Badan sama mengukur Tinggi Badan, setelah itu kita melapor ke kader yang bertugas untuk mencatat hasil penimbangan ke dalam buku KIA, lalu mengambil antrian untuk suntik. Sebelum diberi suntikan bidannya memberikan penyuluhan dulu tentang imunisasi seperti BCG dan Polio, serta teknisi penyuntikannya dan dampaknya.....".

Berdasarkan analisa peneliti bahwa pelaksanaan kegiatan posyandu sudah dilaksanakan dengan baik dan sistem 5 meja sudah terlaksana secara baik.Pembagian tugas bagi kader setiap mejanya sudah baik dan kader sudah mengerti tentang tugas mereka masing - masing.Semua kader tersebut aktif dalam melakukan posyandu setiap bulannya.
Namun pada saat peneliti melakukan observasi peneliti menemukan bahwa pada meja ke - IV (penyuluhan) belum dilaksanakam secara baik oleh kader. Hal ini disebabkan karena kurangnya pengetahuan kader tentang materi - materi kesehatan, kader telah m,endapatkan satu kali pelatihan kader tentang pelaksanaan kegiatan posyandu namun kader belum mendapatkan pelatihan tentang materi - materi posyandu.

\section{Pencatatan dan pelaporan dari hasil pelaksanaan kegiatan posyandu Pada Posyandu Cendrawasih 1 di Wilayah kerja Puskesmas Ikur Koto Tahun 2018.}

Sistem pencatatan dan pelaporan posyandu Cendrawasih 1 sudah dilakukan oleh kader dan Bidan Pembina Wilayah dengan baik. Dari hasil wawancara yang didapatkan dari Tenaga Kesehatan dan koordinator promkes dengan menggunakan panduan wawancara pada posyandu Cendrawasih $1 \mathrm{RW}_{3} \mathrm{RT}_{2}$ di Wilayah Kerja Puskesmas Ikur Koto Tahun 2018 didapatkan bahwa Posyandu Cendrawasih 1 memiliki Data Inventaris Sasaran (DIS) Bayi dan Balita, DIS Ibu Hamil dan DIS Ibu Menyusui. Selain memiliki DIS posyandu Cendrawasih 1 memiliki Register Kohor dengan sistem pencatatan dan pelaporannya yang lengkap. Sebagaimana kutipan dari informen berikut ini :

“....posyandu Cendrawasih 1 ada memiliki DIS Bayi dan Balita, DIS Ibu Hamil dan DIS Ibu Nifas, kalau sistem pemcatatan dan pelaporan posyandu ini insya allah lengkap, bisa dilihat di tempat kader nanti. Kalau banyak sasarannya bisa yona hitung sendiri nanti di register kohortnya....". 
Berdasarkan analisa peneliti bahwa Sistem Informasi Posyandu (SIP) pada posyandu Cendrawasih 1 sudah tersusun secara rapi dan terperinci.Namun pada saat peneliti melakukan observasi peneliti menemukan bahwa jumlah sasaran yang datang tidak sesuai dengan jumlah sasaran yang tidak datang.Dari 103 orang sasaran di posyandu cendrawasih 1 hanya 28 orang $(30 \%)$ sasaran yang datang ke posyandu.

Hal ini didukung oleh hasil penelitian Yolanda Cicilia Eka tahun 2015 menyebutkan bahwa seluruh kader yang mempunyai pengalaman $1-5$ tahun dalam melakukan suatu kegiatan posyandu dapat meningkatkan kinerja posyandu tersebut, sedangkan menurut Notoadmodjo (2007) pengalaman merupakan sumber pengetahuan, dan pengalaman itu merupakan suatu cara untuk memperoleh kebenaran perilaku, sehingga dapat disimpulakan bahwa semakin banyak pengalaman yang dimiliki seseorang maka informasi suatu kegiatan berkembang semakin baik.

\section{KESIMPULAN}

1. Organisasi posyandu pada posyandu Cendrawasih 1 $\mathrm{RW}_{3} \mathrm{RT}_{2}$ di Wilayah Kerja Puskesmas Ikur Koto tidak lengkap karena hanya melanjutkan organisasi posyandu yang telah ada sebelumnya yaitu hasil pemekaran puskesmas Air Dingin. Nama Posyandunya yaitu Posyandu Cendrawasih 1, Posyandu Cendrawasih 1 tidak memiliki Surat Keputusan (SK) pendirian posyadu, struktur organisasi dan tugas pokok dari masing - masing struktur organisasi dan jumlah sasaran sebanyak 103 orang yang terdiri dari ibu hamil, bayi dan balita serta ibu nifas.

2. Persiapan pelaksanaan kegiatan posyandu pada posyandu Cendrawasih $1 \quad \mathrm{RW}_{3} \mathrm{RT}_{2} \quad \mathrm{di}$ Wilayah Kerja Puskesmas Ikur Koto dilaksanakan baru terfokus pada persiapan tempat dan sarana, belum mencakup semua aspek, yaitu kurang tepatnya dala pemasangan sarana dan prasarananya.

3. Pelaksanaan kegiatan posyandu pada posyandu Cendrawasih 1 $\mathrm{RW}_{3} \mathrm{RT}_{2}$ di Wilayah Kerja Puskesmas Ikur Koto ditinjau dari sistem lima meja telah dilaksanakan dengan baik. namun masih ditemukan peran kader yang belum maksimal dalam menjalankan fungsinya sebagai penyuluh di meja IV, sehingga peran ini masih menjadi tanggung jawab Petugas Kesehatan.

4. Sistem pencatatan dan pelaporan posyandu pada Posyandu Cendrawash 1 sudah tersusun secara rapi dan terperinci. Dan posyandu cendrawsih 1 memiliki sistem pencatatan dan pelaporan yang lengkap berupa buku laporan atau disebut juga dengan buku 13.

\section{SARAN}

1. Bagi Puskesmas Ikur Koto

Di harapkan untuk Pengelolaan pelaksanaan kegiatan posyandu dapat melengkapi dokumen pendirian posyandu, seperti : Surat Keputusan (SK), melampirkan Struktur Organisasi Pendirian Posyandu, serta melampirkan tugas pokok dan fungsi dari masing - masing dari 


\begin{abstract}
struktur organisasi posyandu.Diharapkan Posyandu Cendrawasih $\quad 1 \quad$ bisa mempertahankannya dan partisipasi masyarakatnya tetap baik sehingga bida meningkatkan strata posyandunya menjadi strata mandiri.Diharapkan puskesmas ikur koto dapat mengadakan pelatihan kader tentang materi penyuluhan serta organisasi posyandu.
\end{abstract}

2. Bagi petugas kesehatan dan kader pelaksana posyandu dapat dijadikan acuan untuk dijadikan panduan dalam perbaikan dan perkembangan posyandu.

3. Bagi Peneliti Selanjutnya

Diharapkan peneliti selanjutnya agar dapat mengembangkan penelitian ini sehingga pelaksanaan kegiatan Posyandu bisa dilaksanakan dengan lebih baik lagi dan lebih memperhatikan pada pelaksanaan kegiatan posyandunya. Serta dapat melengkapi kekurangan yang ada pada penelitian ini.

\section{DAFTAR PUSTAKA}

Iswarawanti, D. N. (2010). KADER POSYANDU : PERANAN DAN TANTANGAN PEMBERDAYAANNYA

DALAM USAHA PENINGKATAN GIZI ANAK DI INDONESIA. MANAJEMEN PELAYANAN KESEHATAN, 13, 169-173.

Kementrian Kesehatan RI. (2011). Pedoman Umum Pengelolaan posyandu. Jakarta: Kementrian Kesehatan RI.

Kementrian Kesehatan RI. (2012).
Kurikulum dan Modul Pelatihan $K$ ader Posyandu. Jakarta: Kementrian Kesehatan RI.

Padang, D. K. K. (2014). Buku Laporan tahunan. Padang: DKK Padang.

Padang, D. K. K. (2016). Buku Laporan Tahunan. Padang: DKK Padang.

Prasetyawati, A. E. (2012). No Title kesehatan ibu dan anak (KIA). Yogyakarta: Nuha Medika.

Pudiastuti, R. D. (2011). Buku Ajar : Kebidanan Komunitas. Yogyakarta: Nuha Medika.

Rosihan. (2012). Kebijakan Revitalisasi Posyandu di Provinsi Kalimantan Selatan. DIA, Jurnal Publik Administrasi, 10(2), 32-43.

Sugiyono. (2013). METODE PENELITIAN KUANTITATIF, KUALITATIF DAN R \& D. Bandung: ALFABETA.

Sugiyono. (2016). METODE PENELITIAN KUANTITATIF, KUALITATIF DAN KOMBINASI (Mix Methode). Bandung: ALFABETA.

Sulistyorini, C. I. (2010). POSYANDU (POS PELAYANAN TERPADU) DAN DESA SIAGA. Yogyakarta: Nuha Medika.

Wahyuningsih, H. P. (2009). DASAR-DASAR ILMU KESEHATAN MASYARAKAT DALAM KEBIDANAN. Yogyakarta: Fitramaya. 
